\title{
Ocorrência de transtornos metabólicos em vacas leiteiras da Região do Caparaó/ES
}

Felippe Bizarro Silva, Daniel Pacheco Ipólito, Gabriel Ferreira Borges, Matheus Cruz de Oliveira, Heberth de Paula, Mayra Cardozo Mendes, Dirlei Molinari Donatele, Áquila Flavia da Rocha Braga, Ricardo Almeida Marrani, Graziela Barioni"

Centro de Ciências Agrárias e Engenharias, Universidade Federal do Espírito Santo (UFES), Vitória, ES, Brasil

*Autor correspondente

e-mail: grazibari@gmail.com

\section{Resumo}

A vaca leiteira é susceptível aos desequilíbrios metabólicos devido à alta exigência energética, proteica e mineral decorrente da produção de leite, e, caso ocorra um desequilíbrio entre o nível de produção e o consumo do alimento, pode ocorrer a enfermidade. 0 objetivo desse projeto, aprovado pelo Comitê de Ética no Uso de Animais (CEUA - UFES) sob número 003/2015, foi determinar a ocorrência de transtornos metabólicos em vacas em lactação nos municípios da Região do Caparaó/ES. Foram selecionadas aleatoriamente três propriedades leiteiras de manejos similares dos 12 municípios que compõem a Região do Caparaó. Foram coletadas amostras sanguíneas de vacas mestiças Holandês x Zebu, independentemente do estágio de lactação, por punção da veia/artéria coccígea em tubos de coleta a vácuo, sem anticoagulante. As amostras foram transportadas em caixas isotérmicas com gelo reciclável até a chegada ao Laboratório de Grandes Animais (HOVET/UFES) e centrifugadas a 3000gpm durante 10 minutos para a obtenção de soro, os quais foram alicotados em microtubos de polietileno, identificados e congelados a $-20^{\circ} \mathrm{C}$ até o momento das determinações laboratoriais. As determinações de albumina, fósforo inorgânico, magnésio, cálcio e $\beta$-hidroxibutirato (BHB) foram realizadas em aparelho bioquímico automático, seguindo as recomendações de cada kit comercial. Foram avaliadas 422 vacas divididas em seis grupos experimentais: Grupo Cetose, com valores de BHB $\leq$ 0,8 mmol/L; Grupo hipoproteinemia, com valores de albumina < 2,7 g/dL; Grupo hipocalcemia, com valores de cálcio inferior a 7,4 mg/dL; Grupo hipofosfatemia, com fósforo <2,0 mg/dL; Grupo Sau dável (controle), que apresenta para todas as variáveis estudadas os valores dentro da normalidade; Grupo misto, quando o animal apresentava mais de uma enfermidade metabólica. Foram diagnosticadas 161 vacas saudáveis (controle), 89 portadoras de cetose subclínica, 25 portadoras de hipocalcemia, 59 portadoras de hipoproteinemia e 88 com distúrbio metabólico misto; as vacas diagnosticadas com hipofosfatemia também apresentaram outros distúrbios metabólicos, sendo classificadas em distúrbios 
mistos. As alterações metabólicas se justificam como consequência de fatores associados ao consumo efetivo, alterações inerentes ao clima e a outros fatores relacionados à forma de manejo alimentar, sua conservação e fornecimento, e à demanda do organismo. Doenças metabólicas são enfermidades com significativo entrave para a pecuária leiteira capixaba, o que se torna grande preocupação devido aos animais analisados serem portadores da forma subclínica. Por isso, torna-se necessário a prevenção e tratamento dessas patologias para que não se traduzam em dano econômico ao produtor e à cadeia leiteira.

Apoio Financeiro: Fundação de Amparo à Pesquisa e Inovação do Espírito Santo (FAPES). 